\title{
Un largo camino a la edición más completa ${ }^{1}$
}

\author{
Alejandro Ariel González ${ }^{[1]}$ \\ Traductor de Literatura y revolución
}

\begin{abstract}
:
This article comments the translation of Literature and Revolution, by Leon Trotsky, into Spanish.
\end{abstract}

Keywords: Leon Trotsky; Literature and Revolution; Russian Literature

\section{Antecedentes}

Como suele ocurrir con muchos clásicos escritos en lenguas extranjeras, Literatura y revolución es un texto a la vez muy bien y muy mal conocido por los hispanohablantes. Desde su primera traducción al castellano, numerosas editoriales han publicado y publican este título, que ha llegado a convertirse en uno de los más conocidos y leídos de León Trotsky. Esta circunstancia, propicia para aquel que busca conocer la obra y el pensamiento del revolucionario ruso, pierde su original encanto cuando sometemos el libro a los principios textológicos más elementales. Por tales principios entendemos, grosso modo, los siguientes: establecer el origen de la traducción, la fuente original utilizada, el idioma del que se realiza la traducción; cotejar la fuente con otras ediciones en la lengua original, en especial con ediciones publicadas en vida del autor y, si es posible, con los manuscritos; conocer la historia del texto -de sus diversas ediciones y de sus posibles diferencias: agregados, omisiones, pasajes censurados, etc.-; observar los criterios de división del texto original en partes, capítulos, apartados y párrafos; reproducir las notas y la bibliografía originales, indicando su carácter original para distinguirlas de posibles -y deseables- agregados hechos en las sucesivas ediciones por parte de los traductores y editores. En este sentido, una mirada atenta nos permitiría constatar que es más bien poco lo que conocemos sobre Literatura y revolución. Por descuido, por negligencia o por precipitación, las ediciones castellanas de este libro han ignorado estos aspectos, que resultan fundamentales para el lector interesado en saber si está ante una traducción completa, fidedigna, confiable del original. Lamentablemente, en ese camino que conduce de la creación del autor a la apropiación del lector en lengua extranjera se pierden innumerables dimensiones que tornan difícil, luego, restablecer o reconstituir el pensamiento y el estilo originales de una obra. En términos generales, quien desee emprender esta tarea tendrá que conocer las diferentes ediciones existentes en su lengua y en la lengua original para poder determinar la mayor o menor fidelidad con la que el texto

\footnotetext{
${ }^{1}$ Extracto del prólogo de Alejandro Ariel González, traductor, a la edición de Literatura y revolución, de Trotsky, editado por Ediciones RyR
}

Hasta hoy, el mundo hispanohablante ha conocido la mitad del texto original tal como fue concebido por su autor en 1923, y en general tampoco ha accedido a su formato inicial. El traductor de la reciente edición directa del ruso, nos explica algunas de las peripecias que debió sufrir el texto original. 
ha llegado hasta nosotros - sin mencionar las frecuentes ediciones en lenguas "intermedias" que, cual puntos fronterizos (o mejor: aduaneros, con el correspondiente tributo lingüístico), el texto ha debido sortear en su itinerario.

Las numerosas ediciones castellanas de Literatura y revolución responden mal -o no responden- a los criterios arriba citados. A menudo no indican el idioma del que se ha realizado la traducción, no aclaran si se trata de una nueva traducción o si han tomado una ya publicada anteriormente, no señalan la fuente original y de la historia del texto no dicen ni una palabra. El resultado era inevitable: hasta hoy, el mundo hispanohablante ha conocido la mitad del texto original tal como fue concebido por su autor en 1923, y en general tampoco ha accedido a su formato inicial. Veamos esto con mayor detalle.

Los diferentes Literatura y revolución que circulan en nuestro medio presentan una primera parte relativamente coherente, "orgánica", que aborda la problemática de la literatura en la incipiente República Soviética. Allí aparecen los conceptos y reflexiones de Trotsky más conocidos en ese terreno: los "compañeros de ruta" de la revolución, el futuro de la literatura proletaria, de las vanguardias, de los nuevos movimientos artísticos, el papel del partido en el arte, etc. A continuación, encontramos una segunda parte compuesta por artículos sobre arte, literatura, cultura y ciencia; esta segunda parte es la que más difiere entre las distintas ediciones, tanto por la selección como por la cantidad de los artículos publicados. De esta forma, a todos ha quedado claro que el Literatura y revolución salido de la pluma de Trotsky es solo la primera parte del libro, mientras que esa segunda parte, tan variada entre las distintas ediciones, es una recopilación de artículos conformada de acuerdo a criterios más o menos arbitrarios de los editores. Ahora, ¿qué hay de cierto en todo esto?

Trazar la genealogía en lengua castellana de Literatura y revolución nos lleva a su primera edición, publicada en Madrid en 1923 por la editorial Aguilar. Se trata de una traducción no directa del ruso, sino del alemán. Esta edición -no sabemos si por decisiones de los editores españoles o debido a que la fuente en alemán ya estaba asíreproduce menos de la mitad del original ruso: omite por completo la segunda parte, y en la primera tampoco incluye todos los capítulos presentes en el original ruso, alterando, además, su orden. Esta edición volvió a ser publicada por la misma casa editora en 1930. De alguna manera, constituye una suerte de "prehistoria" en las ediciones castellanas de Literatura y revolución, ya que pasarían largos años hasta que 
otra editorial volviera a publicar el libro. Recién en 1964 la editorial Jorge Álvarez publicó en Buenos Aires lo que sería la tercera edición del libro y su segunda traducción, mientras que en 1969 Ruedo Ibérico publicaba en París la cuarta edición y la tercera traducción. Estas últimas dos ediciones surgieron al calor del auge de las traducciones de los escritos de Trotsky al francés, y la segunda de ellas -creemos- debe en buena medida su estructura a la edición francesa del libro (Littérature et Révolution, Paris, Julliard, 1964). Respecto a la fuente que tomaron ambas ediciones, no queda más que hacer conjeturas. El libro ya hacía tiempo estaba prohibido en la Unión Soviética, y conseguir un ejemplar por esos años era una tarea prácticamente imposible. Es casi seguro que la traducción de Jorge Álvarez - con prólogo de Jorge Abelardo Ramos- no está hecha del ruso; en cuanto a Ruedo Ibérico, se hace difícil decir de dónde se hizo la traducción, ya que, al parecer, entre los traductores había quien sabía ruso, pero, por otro lado, en la edición no se especifica que la traducción fuera directa de dicha lengua, descuido importante si era efectivamente así. En ambos casos, estas ediciones fundaron, por así decir, lo que sería una tradición en la publicación y en la recepción del libro. Ambas reproducían una primera parte que, cabía entender, era propiamente Literatura y revolución, y una segunda parte compuesta por artículos de Trotsky escritos, en su inmensa mayoría, después de 1923, año de publicación de su libro. Estas dos traducciones fueron reimpresas una y otra vez por diferentes editoriales en América Latina y en España. Es difícil rastrear todas y cada una de las ediciones castellanas de Literatura y revolución, pero en principio podemos afirmar que la mayoría de ellas ha seguido o bien la traducción de Jorge Álvarez o bien la de Ruedo Ibérico.

Sin embargo, en este mosaico de ediciones es posible establecer algunos hechos. Primero, el que ya nos hemos anticipado a anunciar, y es que todas las ediciones castellanas han ignorado la segunda parte del original ruso de 1923. Segundo, que esa primera parte que sí fue publicada difiere notablemente entre las distintas ediciones en cuanto al contenido y a la estructura del texto. Tercero, que los escritos de Trotsky sobre arte, cultura, ciencia y literatura incluidos en los apéndices no responden a ningún criterio de ordenamiento, sea este cronológico o temático: artículos de distintas épocas y lugares aparecen allí poco menos que "amontonados", uno al lado del otro, lo que de alguna manera dificulta el seguimiento de ciertas ideas, reflexiones y preocupaciones del autor a lo largo de los años; como la selección de artículos tampoco es exhaustiva, muchas líneas del pensamiento del autor quedan truncadas en esas ediciones. Cuarto, 
que en lengua castellana no hay traducciones completas de Literatura y revolución hechas a partir del original ruso. ${ }^{[2]}$

¿Cómo fueron posibles tantos descuidos? No es nuestra tarea resolver esta cuestión. Por algún motivo, esa segunda parte del original ruso no llegó a Occidente, o llegó y fue descartada desde el comienzo, por lo que no se la reprodujo en ediciones posteriores. Esto no deja de resultar curioso, porque el texto original no fue publicado en dos tomos (lo que permitiría pensar que acaso el segundo tomo simplemente se perdió), sino en un solo libro; por lo visto, mediaron razones editoriales, o quizás de otra índole. Lo que nos importa ahora es restablecer el texto original tal como fue concebido por su autor en 1923.

\section{Literatura i revoliutsia}

Veamos un poco la historia de este libro en la ex Unión Soviética y en la actual Rusia. Hasta la fecha, existen tres ediciones de Literatura i revoliutsia. Las dos primeras salieron en vida de Trotsky, con solo un año de diferencia. La primera data de 1923, la segunda de 1924. Como es sabido, hacia 1928 los trabajos de Trotsky fueron prohibidos y censurados. Solo en 1991 salió la tercera edición, que reproduce íntegramente la primera.

Cabe detenerse en algunos detalles de las dos primeras ediciones, tan poco conocidas en Rusia, por no decir en Occidente. La primera de ellas, como dijimos, fue publicada en el año 1923 por la editorial Krásnaia Nov, dependiente del Comité Central de Instrucción Política, en Moscú, con una tirada de 25.000 ejemplares y un volumen de 396 páginas. En 1924, la Editorial Estatal, con sede en Moscú, volvió a publicar una segunda edición aumentada de Literatura $i$ revoliutsia, con una tirada de 10.000 ejemplares y un volumen de 424 páginas. ${ }^{[3]}$ Ambas ediciones incluyen un prólogo de Trotsky donde se explica el origen, la naturaleza, los criterios de compilación y la relación entre las dos partes del libro. Dicho prólogo llegó cercenado hasta nosotros, y aquí lo reproducimos completo por primera vez. Veamos por partes qué señala Trotsky en él:

"Los capítulos dedicados a la literatura actual, que componen la primera parte del libro, fueron concebidos unos dos años atrás como prólogo para viejos artículos, pero dicho trabajo se amplió con creces durante el descanso veraniego del año '22. Siguió inconcluso hasta el verano del año '23. Hemos tenido que completar y reelaborar significativamente los esbozos del año pasado sobre la base del nuevo material literario. Sin embargo, también ahora, desde luego, distan mucho de estar acabados y completos...” 
De aquí, naturalmente, deriva una primera conclusión, y es que Literatura $i$ revoliutsia no fue concebido desde un principio como libro. Trotsky fue reuniendo material que ya tenía escrito y lo iba ajustando y corrigiendo de acuerdo a los rápidos cambios que se producían en la arena literaria de aquellos años. No hay que perder de vista que Trotsky llevaba entonces una intensa actividad política que le dejaba muy poco tiempo para la crítica literaria. No es de extrañar, entonces, que el libro carezca de unidad de conjunto, que no presente un abordaje sistemático de la cuestión que estudia o que puedan encontrarse reiteraciones a lo largo de él.

Con respecto a la segunda parte, Trotsky dice:

"En la segunda parte del libro se han reunido artículos que comprenden -sin sistema alguno- el período interrevolucionario (1907-1914) [...] Los artículos de la segunda parte abarcan, en modo alguno agotándolo, el período de transformación egoísta, de "refinamiento" estético, de individualización y aburguesamiento de la intelliguentsia [...] La relación entre la primera y la segunda parte del libro reside en que el arte de transición, es decir el actual, hunde todas sus raíces en el ayer, en la víspera prerrevolucionaria. La relación también viene dada por la unidad de la concepción marxista del autor."

Este pasaje es importante por dos motivos. Primero, porque refleja que, a pesar de que Literatura i revoliutsia no fue pensado como libro, Trotsky intenta darle un carácter orgánico, coherente, para que no se convierta en una mera antología de artículos críticos. Segundo, porque para ello Trotsky decide trazar una genealogía de los cambios que estaban teniendo lugar. En este sentido, Trotsky traza un criterio metodológico para confrontar con los movimientos de vanguardia: mientras estos creen partir desde la nada, o más bien desde la ruptura con lo "viejo", Trotsky no se deja llevar por ilusiones y analiza el recorrido espiritual e intelectual de la intelliguentsia desde la derrota de 1905. Será esta profundidad, esta perspectiva histórica, la que otorgará un plus a Trotsky en sus discusiones con los representantes de los nuevos movimientos literarios.

Sin embargo, más allá de las intenciones de Trotsky y de su penetrante mirada histórica, podemos afirmar que el libro adolece efectivamente de un principio único de comprensión del fenómeno literario. Trotsky, cabe decirlo, no funda aquí una estética; más bien, lo que hace es balancearse entre consideraciones estrictamente políticas ("los compañeros de ruta", los "campesineadores", etc.) o bien propiamente artísticas, basándose en las corrientes literarias de su época (realismo, simbolismo, futurismo, etc.). Por otro lado, la unidad de la concepción marxista de la que habla Trotsky debe 
ser comprendida dentro de lo que el marxismo prerrevolucionario significaba en Rusia, y no tanto desde los postulados teóricos del marxismo occidental. Trotsky mantuvo un sentimiento de hostilidad hacia la evolución posterior del marxismo europeo, tanto en su plano teórico como político-programático. No toma de él ningún concepto ni ninguna clave de interpretación adecuada para leer la realidad rusa. Eso ya lo tenía a mano. Trotsky es heredero de aquella tradición crítica literaria e ideológica que se iniciara en Rusia hacia mediados del siglo XIX con Vissarión Grigórievich Bielinski y que cobraría fuerzas a partir de los años '60 con los trabajos de Nikolái Aleksándrovich Dobroliúbov y Dmitri Ivánovich Písarev, con las indagaciones filosóficas de Nikolái Gavrílovich Chernishevski, con los escritos de Aleksandr Ivánovich Herzen, con el desarrollo del movimiento populista, con la apropiación de la obra de Marx por parte de Gueorgui Valentínovich Plejánov, con el movimiento bolchevique. Bien mirado, Trotsky está en diálogo permanente con esta tradición, que es a la que él mismo pertenece, aquella en la que creció y lo justifica.

\section{Estructura}

La edición de Literatura y revolución que el lector tiene en sus manos se compone de dos secciones. La sección I es la traducción del original ruso completo de Literatura i revoliutsia. Primero tradujimos el texto desde la edición tercera del libro (1991), publicada en Moscú por la Editorial de Literatura Política (Izdátielstvo politícheskoi literaturi), preparada y prologada por Iuri Bóriev. Luego cotejamos esta tercera edición con las primeras dos ediciones. Así, descubrimos que entre la primera y la tercera edición no hay prácticamente diferencias: solo algunas correcciones ortográficas y de puntuación dictadas por las normas del ruso contemporáneo, que difieren ligeramente de las del ruso de comienzos de los años '20. En cambio, en la segunda edición sí encontramos dos diferencias con respecto a la primera: una nota del propio Trotsky a esa segunda edición y el agregado de un capítulo a la primera parte. Hemos tomado la decisión de seguir el ordenamiento de esta segunda edición, la última publicada en vida de Trotsky.

La sección II, "Escritos sobre literatura, arte y cultura”, reúne prácticamente todos los artículos, cartas y notas de Trotsky dedicados a esos temas, ordenados cronológicamente. Esta segunda sección ha sido dividida en función de los hechos más significativos en la historia rusa del siglo XX y en la biografía de su autor. En primer lugar, hemos incluido los artículos publicados por Trotsky antes de la primera revolución de 1905. Al respecto, recordemos lo que el autor dice sobre ellos en el prólogo a Literatura i revoliutsia: 
"No he incluido aquí los artículos de crítica literaria anteriores a la revolución de 1905. Por dos motivos: primero, aquella era otra época, radicalmente diferente, y segundo, en los artículos mismos había aún mucho de principiante."

Efectivamente, aquella era otra época; pero, una vez más, nos permite comprender los años que la siguieron. La crítica literaria de Trotsky anterior a 1905 es prácticamente desconocida en Occidente; se trata de un Trotsky joven iniciándose en el ejercicio de la escritura y de la polémica. Esta primera parte recoge todos los artículos publicados por Trotsky en el periódico Vostóchnoie obozrenie entre 1900 y 1902. Como el lector verá, encierran dos grandes ejes temáticos: el análisis y la crítica de los escritores y pensadores rusos del siglo XIX y comienzos del XX (Herzen, Dobroliúbov, Gógol, Uspenski, Zhukovski, Andréiev, entre otros), y de las figuras más destacadas de Occidente (Nietzsche, Hauptmann, Ibsen, Arthur Schnitzler). Asistimos aquí a los orígenes mismos del pensamiento de Trotsky, lo vemos abrevando en su rica tradición nacional y mirando permanentemente a Europa; en este sentido, Trotsky se inicia como un típico miembro de la intelliguentsia rusa. ${ }^{[4]}$ Con excepción del artículo "N. V. Gógol”, el resto de los que componen este primer apartado se publica por primera vez en lengua castellana.

El segundo apartado de la sección II comprende artículos escritos entre 1908 y 1916, es decir, artículos publicados entre la revolución de 1905 y la de 1917; la gran mayoría de los escritos de Trotsky sobre literatura en ese período componen justamente la segunda parte de Literatura i revoliutsia; aquí publicamos los que no fueron incluidos allí.

El tercer apartado reúne los artículos escritos entre 1917 y 1929, año en que Trotsky es desterrado de la Unión Soviética. Allí podemos ver cómo cambia el eje de las preocupaciones relativas a la literatura y el arte. Ya tomado el poder, la cuestión se centraba ahora en cómo promover el desarrollo cultural de las masas campesinas y proletarias. Tres de estos artículos ("No solo de 'política' vive el hombre", "Para reconstruir el modo de vida es preciso conocerlo" y "La lucha por un lenguaje culto") fueron publicados en 1923 -casi conjuntamente con Literatura y revolución- en una antología preparada por el propio Trotsky, con el nombre Problemas de la vida cotidiana, de la que existen varias ediciones castellanas. 
El cuarto apartado incluye los artículos escritos entre 1930 y 1940, año de su asesinato. Aquí el lector encontrará la mayor parte de los artículos que ya han sido publicados como apéndice en ediciones anteriores de Literatura y revolución. Comprenden, entre otras cosas, la actividad de Trotsky en México, su amistad con Diego Rivera, su disputa con Malraux, su crítica a la burocracia stalinista en el terreno del arte, el manifiesto en coautoría con André Breton. Como novedad, hemos tenido el cuidado de publicar todos estos artículos siguiendo un riguroso orden cronológico.

En el Apéndice hemos incluido las páginas del diario de exilio de Trotsky concernientes a escritores (1935). Al final, el lector encontrará, como anexo, una lista detallada de los principales periódicos y revistas que aparecen mencionados en esta edición; creímos que era importante brindar información sobre este aspecto, ya que el lector contemporáneo no conoce los nombres, la relevancia y la orientación política e ideológica de los órganos de prensa de aquella época.

\section{Criterios de selección}

Hemos consultado en profundidad la bibliografía de Trotsky existente en la Biblioteca Nacional de Rusia, con sede en San Petersburgo. Allí fuimos haciendo una primera selección de los materiales partiendo de los títulos mismos de los textos: todo lo que tuviera o pudiera tener alguna relación con el tema de "literatura y revolución" fue anotado para su lectura. De este modo, entre las fuentes impresas y digitales reunimos un total de aproximadamente 900 artículos, cartas, discursos, etc., del que seleccionamos un corpus de alrededor de 150. En su mayoría, y por suerte, tales artículos ya venían a su vez compilados en publicaciones temáticas, lo que nos simplificó, en parte, el trabajo. Con todo, muchos artículos forman parte de textos más extensos, o que a primera vista -en algunos casos- no parecen guardar relación con lo que nos interesaba, y llegar a ellos, leerlos y clasificarlos ("corresponde o no corresponde para la edición") supuso un arduo trabajo.

Como criterio rector hemos preferido guiarnos por el título de la obra, Literatura y revolución. Es decir, nos hemos enfocado en aquellos artículos que tuvieran una relación directa o casi directa con este tema. Ello no siempre ha sido sencillo. Hay artículos de Trotsky dedicados en principio a otras cuestiones, pero en ciertos pasajes de ellos hay alusiones o citas vinculadas a la literatura, o a algún escritor en especial, lo que nos llevaba a dudar acerca de incluirlos o no. A grandes rasgos, hemos seleccionado todos los artículos de Trotsky en los que la literatura fuera, si no el eje de la reflexión, sí al menos una de sus preocupaciones centrales. Allí donde la literatura aparece velada, ocupando un lugar secundario, a modo de ejemplo o de cita erudita, hemos tomado la decisión de no incluir el texto. 
No obstante, el lector encontrará también otros temas que no guardan directa relación con la literatura: en esto nos ha ayudado el propio Trotsky. Él incluyó en la segunda parte de Literatura $i$ revoliutsia artículos que caracterizaban la atmósfera cultural que se respiraba en las grandes ciudades, con sus vanguardias y sus movimientos artísticos (véase, por ejemplo, "Sobre la muerte y Eros" o "Conversación de Año Nuevo sobre el arte"); esta circunstancia nos permitió también a nosotros incluir, en la sección II, artículos suyos que enfocan aspectos culturales y cotidianos concomitantes con los fenómenos artísticos.

En esta edición no hemos incluido los artículos de Trotsky sobre ciencia y técnica publicados en otras ediciones castellanas de Literatura y revolución; es evidente que no guardan relación alguna con el tema.

\section{Perspectivas}

La investigación y la búsqueda de fuentes originales en lengua rusa está dando sus provechos. La caída del régimen soviético, por un lado, y la consecuente y paulatina apertura de archivos clasificados, por el otro, está dando a conocer en primer lugar al público ruso una larga serie de textos, obras y documentos que durante décadas permanecieron prohibidos, censurados y guardados bajo siete llaves. Desde 1991, filólogos, bibliotecarios, historiadores, sociólogos y demás profesionales vinculados a las ciencias humanas (y no solo) vienen redescubriendo el legado de autores y pensadores caídos en desgracia ante la línea oficial del Partido Comunista Ruso. Vuelven a publicarse sin censuras -o se publican por primera vez- los trabajos de Lev Vigotski, de Ósip Mandelshtam, de Nikolái Gumilióv y de una larga lista de escritores, poetas, teóricos sociales, pensadores y políticos.

León Trotsky forma parte de esa lista, y es casi seguro que fue el que más sufrió la censura en la ex Unión Soviética, dado que fue una las personalidades más odiadas y temidas por el régimen. En su caso, no sólo sus trabajos desaparecieron de todas las bibliotecas, archivos y universidades, sino que incluso era habitual modificar aquellos documentos en los que su nombre aparecía mencionado. Este criterio no se detenía ante nada; por ejemplo, en las Obras Completas de Lenin faltan 50 documentos de los 172 que Lenin le enviara a Trotsky entre 1918 y 1922; esos documentos se conservan en los archivos de Trotsky de distintos países: Estados Unidos, Holanda, Inglaterra. En cambio, los documentos del período de desacuerdo entre Lenin y Trotsky, que comenzó tras el II Congreso del Partido Obrero Socialdemócrata Ruso y terminó con la revolución de 1917, fueron puestos allí en primer plano. En esos documentos Lenin y Trotsky se permitían dirigirse mutuamente expresiones fuertes y ásperas, y Stalin aprovechó presuroso esa circunstancia. Ya durante los primeros veinte años del siglo 
XX Trotsky había oído en reiteradas ocasiones reproches acerca de su brusco cambio de orientación. Una vez caído en desgracia, esos reproches se convirtieron en condena. Otro ejemplo ilustrativo de cómo funcionaba la historiografía soviética: en los tomos tercero, cuarto y quinto de una obra llamada La Revolución de 1917, publicada entre 1924 y 1926 por Istpart (Comisión de Historia de la Revolución de Octubre y del Partido Comunista Ruso, creada en 1920), el nombre de Trotsky aparece mencionado 109 veces, mientras que el de Stalin 10; sin embargo, en el correspondiente artículo de la enciclopedia La Gran Revolución Socialista de Octubre, publicada en 1987, Trotsky aparece citado como una persona que propugnaba la dilación del levantamiento popular, lo que amenazaba con frustrarla (en realidad, la intención de aplazar el levantamiento venía dictada por el deseo de legitimarlo, ya que, en opinión de Trotsky, el pueblo confiaba en los sóviets y su popularidad más que en la influencia de los bolcheviques, y un levantamiento sancionado por los sóviets tendría más posibilidades de alcanzar un apoyo amplio).

Como vemos, hay mucho por reconstruir, empezando por las fuentes originales. Para el caso de Rusia y de Literatura i revoliutsia, reproducimos aquí las palabras de Iuri Bóriev en su prólogo a la tercera edición:

"La historia de la literatura soviética, la historia de la política cultural del partido en el ámbito de la literatura, la historia de las investigaciones metodológicas de la crítica nacional y extranjera, y el propio proceso históricoliterario, son imposibles de concebir cabal y plenamente sin el libro de Trotsky Literatura y revolución".

En lo que hace a los países occidentales, creemos que estos emprendimientos deben servir como estímulos para revisar también las ediciones y las traducciones con las que nosotros contamos. La presente edición de Literatura y revolución pretende ser un aporte en esa dirección.

\section{NOTAS}

[1] Sociólogo y especialista en Rusia, donde residió entre 2005 y 2014. Se dedica a la traducción desde 2003. Ha publicado artículos en Rusia, Argentina y México sobre teoría social, traducción y literatura rusa (en particular Dostoievski). Ha ganado premios 
de ensayo, literatura y traducción en Argentina y en Rusia. Participa frecuentemente en congresos y conferencias internacionales de eslavística y traducción. Forma parte del programa Lectura Mundi-SEPTeSA de la Universidad Nacional de San Martín.

[2] Estas circunstancias, por otra parte, no son privativas del mundo hispanohablante, ya que Occidente en general ha conocido, extrañamente, solo la primera parte del libro. De hecho, así se lo puede encontrar en las ediciones inglesas, francesas e italianas hasta la actualidad, tanto en ediciones gráficas como digitales. Solo hemos encontrado una traducción fiel de la primera edición de Literatura y revolución en una edición alemana que data de 1994.

[3] Esta segunda edición es muy poco conocida, creemos que debido a su escasa tirada. Las primeras dos ediciones de Literatura $i$ revoliutsia pueden encontrarse en la Biblioteca Nacional de Rusia, San Petersburgo, con el código de ubicación 89-7/319 y 89-5/2887 respectivamente.

[4] Así lo rememora Trotsky en su libro Mi vida: “A poco de llegar a Ust-Kut, comencé a colaborar en un periódico de Irkutsk, llamado Vostóchnoie Obozrenie. Era un periódico provinciano autorizado por la censura que los viejos populistas habían creado en el destierro y del que por el momento se habían adueñado los marxistas. Yo empecé enviando correspondencias de la aldea, aguardé con cierta emoción a que apareciese la primera y, animado por los redactores, me pasé a los ensayos y a la crítica literaria. Abrí al azar un diccionario italiano para ver si encontraba un seudónimo y di con la palabra "antídoto"; durante muchos años firmé mis artículos con este nombre (Antid Oto). A mis amigos se lo explicaba en broma, diciendo que se trataba de poner un poco de contraveneno marxista en la Prensa autorizada. Cuando menos lo esperaba, el periódico me subió los honorarios de dos a cuatro kópeks la línea. ¿Qué mejor muestra de reconocimiento? Mis artículos versaban sobre los campesinos y los clásicos rusos, sobre Ibsen, Hauptmann y Nietzsche, sobre Maupassant y Estaunié, sobre Leonid Andréiev y Gorki. Me pasaba las noches en vela puliendo las cuartillas línea a línea, en busca de la idea precisa o de la palabra adecuada. Y así fui haciéndome escritor”. 